\title{
Control concreto de constitucionalidad y matrimonio civil igualitario en Ecuador ${ }^{* * *}$
}

\section{Concrete control of constitutionality and the same sex civil marriage in Ecuador}

RESUMEN

El artículo trata sobre el reconocimiento constitucional del matrimonio entre parejas del mismo sexo en Ecuador. Para ello estudia los contenidos fácticos, jurídicos e interpretativos de las sentencias 010-18-CN y 011-18$\mathrm{CN}$, expedidas por la Corte Constitucional de Ecuador. Resalta al respecto la importancia que suponen las decisiones constitucionales que plantean una transformación en la interpretación constitucional, la cual tradicionalmente había adjudicado respuestas jurídicas, ya fuera a casos fáciles o difíciles, sobre la base de una interpretación literal. Propone así, en lugar de esta última, una construcción progresiva de la toma de decisiones constitucionales desde una dimensión dinámica e integral que atienda efectivamente a la Constitución y los instrumentos internacionales de derechos humanos. Finalmente, el estudio muestra los desacuerdos interpretativos atinentes a los casos examinados, analizando las razones por las cuales se reconoció este derecho vía control de constitucionalidad y no a través de una reforma a la Constitución.

Doctor en Derecho Constitucional Universidad de Sevilla. Decano de la Facultad de Derecho y Ciencias Sociales de la Universidad UTE, Quito. Profesor de Derecho Constitucional de la Universidad Andina Simón Bolívar, Quito. Contacto: jorgei.benavides@ute.edu.ec ORCID: 0000-0001-7496-891X.

** Doctor en Derecho por la Universidad Andina Simón Bolívar. Vicerrector del Instituto de Altos Estudios Nacionales (Quito, Ecuador). Profesor de Derecho Constitucional. Contacto: jhoel.escudero@iaen.edu.ec -marlin99x@gmail.com ORCID ID: 0000-0002-4776-6615.

**** Recibido el 19 de noviembre de 2019, aprobado el 12 de junio de 2020.

Para citar el artículo: Benavides Ordóñez J. y Escudero Soliz, J. Control concreto de constitucionalidad y matrimonio civil igualitario en Ecuador. En Revista Derecho del Estado, Universidad Externado de Colombia. N. . 47, septiembre-diciembre de 2020, 145-175.

DOI: https://doi.org/10.18601/01229893.n47.05 
PALABRAS CLAVE

Corte Constitucional, control concreto de constitucionalidad, sentencias constitucionales, interpretación constitucional, bloque de constitucionalidad, matrimonio entre personas del mismo sexo.

\section{ABSTRACT}

The article is about the constitutional recognition of same-sex marriage in Ecuador. Study, in this sense, the factual, legal and interpretative contents developed by sentences $010-18-\mathrm{CN}$ and $011-18-\mathrm{CN}$, issued by the Constitutional Court of Ecuador. Thus, the importance of constitutional decisions that pose a transformation in constitutional interpretation, which has traditionally been adjudicating legal responses to easy or difficult cases from the literal interpretation, and instead proposes, a progressive construction of the decisionmaking process is highlighted. Constitutional decisions, from a dynamic and integral dimension based on the Constitution and the International Human Rights Instruments. Finally, the study shows the interpretative disagreements pertaining to the case, analyzing the reasons why this right was recognized via constitutionality control and not through amendment of the Constitution.

\section{KEYWORDS}

Constitutional Court, Concrete constitutional control, Constitutional sentences, Constitutional interpretation, Constitutional block, Same sex marriage.

SUMARIO

Introducción. 1. El control de constitucionalidad en Ecuador. 2. Análisis del Caso 11-18-CN, que permite el matrimonio civil igualitario con efecto inter partes. 2.1. Hechos del caso. 2.2. La importancia del derecho internacional de los derechos humanos para el constitucionalismo ecuatoriano. 2.3. Derecho a la igualdad. 2.4. Libre desarrollo de la personalidad. 3. Análisis del Caso 10-18-CN, que permite el matrimonio civil igualitario con efectos generales. 3.1. Hechos del caso. 3.2. La interpretación constitucional: la literalidad e intencionalidad frente a la comprensión integral y dinámica de la Constitución. 3.3. Derecho a la igualdad y los tipos de democracia aplicados a la sentencia del matrimonio entre parejas del mismo sexo.3.3.1. El rol de la democracia en el caso del matrimonio igualitario. 3.3.2. El derecho a la igualdad.3.3.3. La incidencia de la Opinión Consultiva OC-24/17 en el bloque de constitucionalidad de la Constitución de Ecuador. 4. Balance crítico de las sentencias: mutación o reforma, interpretación literalista o sistemática. Conclusiones. Referencias. 
INTRODUCCIÓN

El reconocimiento del derecho a contraer matrimonio entre parejas del mismo sexo es una exigencia del Estado constitucional y democrático de nuestros días. Varios Estados así lo han reconocido, sea por la vía de la intervención de sus altas cortes -tal es el caso de Colombia o Estados Unidos-, sea por medio de la actuación del Parlamento -y este es el caso de Argentina o España-; o, incluso, por medio del ejercicio de instrumentos de democracia directa -como ocurrió con el referéndum en Irlanda-, aunque la aprobación por esta vía ha sido la excepción. En cualquier caso, lo importante del reconocimiento es que ha permitido poner fin a una discriminación injustificada, sobre la base de una categoría sospechosa como es la opción sexual. De ahí que una constante esgrimida para el reconocimiento haya sido que la imposibilidad de poder contraer matrimonio entre parejas del mismo sexo atenta, entre otros derechos, contra la igualdad y la autonomía, concretizada esta en el libre desarrollo de la personalidad. En consecuencia, existen suficientes razones, que sobrepasan las jurídicas, para garantizar el matrimonio a parejas del mismo sexo.

Por otro lado, generalmente las disposiciones que desarrollan la institución del matrimonio han sido de tipo legal, es decir que en el texto constitucional lo único que se hace es garantizar el derecho de las personas a contraer matrimonio, sin que se entre a establecer mayores detalles; sin embargo, el texto constitucional ecuatoriano de 2008 presenta una singularidad, en la medida en que en el artículo 67 establece que el matrimonio es entre un hombre y una mujer. Dicha regulación, por tanto, en principio daría cuenta de que el poder para contraer matrimonio es un derecho reconocido, exclusivamente, a parejas de distinto sexo, lo cual entraría en conflicto con una interpretación integral de la Constitución, así como de los instrumentos internacionales de derechos humanos.

El presente artículo trata sobre el reconocimiento constitucional, vía justicia constitucional, del matrimonio entre parejas del mismo sexo en Ecuador. Estudia, por tanto, los contenidos fácticos, jurídicos e interpretativos desarrollados por las sentencias $010-18-\mathrm{CN}$ y $011-18-\mathrm{CN}$, expedidas por parte de la Corte Constitucional de Ecuador. Así, se resalta la importancia que suponen las decisiones constitucionales que plantean una trasformación en la interpretación constitucional, la cual venía tradicionalmente adjudicando respuestas jurídicas a casos fáciles o difíciles desde la interpretación literal, y en su lugar propone una construcción progresiva de la toma de decisiones constitucionales, desde una dimensión dinámica e integral a partir de la Constitución y de los instrumentos internacionales de derechos humanos. Finalmente, el estudio muestra los desacuerdos interpretativos atinentes a los casos, analizando las razones por las cuales se reconoció este derecho vía control de constitucionalidad y no a través de una reforma a la Constitución. 
La Constitución de Ecuador de 2008 contempla un profuso sistema de control constitucional, el cual garantiza la supremacía, así como la fuerza normativa de la Constitución y los derechos. En este sentido, el constituyente, por un lado, estableció un control abstracto, el cual en su modalidad previa va dirigido, por ejemplo, a las consultas populares, así como a los tratados internacionales; en tanto que la modalidad posterior supone el control de constitucionalidad de, por ejemplo, la ley, los actos administrativos de efectos generales o los estados de excepción (art. 436). Por otro lado, el control concreto faculta a los jueces para que con motivo del conocimiento de una causa, y ante la duda motivada y razonable de que una disposición infraconstitucional pueda resultar contraria al texto constitucional, suspendan la causa y eleven consulta ante la Corte Constitucional. Dicha consulta puede ser realizada de oficio por el juez o a solicitud de parte (art. 428). De la lectura de la normativa tanto constitucional como legal ${ }^{1}$ daría la impresión de que estamos, en principio, frente a una modalidad de control mixto, en la medida en que, a la par del control concentrado llevado a cabo por la Corte Constitucional, los jueces podrían inaplicar disposiciones contrarias al texto constitucional ${ }^{2}$. En efecto, la posibilidad de que el juez consulte a la Corte operaría ante la duda motivada y razonable, en consecuencia, por el principio de aplicación directa de la Constitución (art. 11.3); mientras que cuando un juez no tenga duda estaría facultado para dejar de aplicar aquella disposición que a su criterio sea inconstitucional. Sin embargo, la posibilidad de inaplicación por parte de los jueces fue impedida por la propia Corte en varias sentencias expedidas en el año $2013^{[3]}$, en las cuales señala, entre otras cosas, la facultad exclusiva de la Corte para realizar control constitucional, transformando así dicho control, en Ecuador, en un control exclusivamente concentrado. De este modo, los jueces no tienen, a partir de los señalados pronunciamientos de la Corte, posibilidad alguna de inaplicar una disposición que con motivo del conocimiento de una causa consideren contraria a la Constitución. De ahí que los jueces, en virtud del principio de aplicación directa de la Constitución, puedan proceder a aplicar directamente las disposiciones constitucionales cuando exista un vacío o se presente alguna ambigüedad normativa, pero no

1 Véanse los artículos 74, 75, 141 y 142 de la Ley Orgánica de Garantías Jurisdiccionales y Control Constitucional (LOGJCC), los cuales dan cuenta del control abstracto y del control concreto de constitucionalidad, respectivamente.

2 Cabe decir que, por ejemplo, en el texto constitucional de 1998, en Ecuador existía el control mixto de constitucionalidad: por un lado actuaba en el control abstracto el entonces Tribunal Constitucional, antecedente de la actual Corte Constitucional, y, por otro, los jueces que ostentaban el control difuso, al estar facultados para inaplicar disposiciones infraconstitucionales que violaran la Constitución (art. 274).

3 Véase, p. ej., Ecuador. Corte Constitucional. Sentencias 001-13-sCN-CC, 6 de febrero de 2013; 005-13-sCN-CC, 28 de febrero de 2013, y 034-13-sCN-CC, 30 de mayo de 2013. 
en casos de contradicción entre la ley y la Constitución o entre aquella y los instrumentos de derechos humanos.

Era necesario explicar, sucintamente, el tipo de control constitucional en general y el tipo de control concreto en particular que existe en Ecuador, para poder llevar a cabo el análisis de las sentencias de la Corte, toda vez que los casos que viabilizan el matrimonio civil igualitario aluden al control concreto, en la medida en que tienen su origen en dos consultas de constitucionalidad, consulta prevista, como ha sido dicho, en el artículo 428 de la Constitución. Dichas consultas fueron formuladas por un tribunal superior de apelación y por un juez ordinario. Como se verá más adelante, la consulta absuelta al tribunal superior tuvo efecto inter partes (Caso 11-18-CN), en tanto que la consulta absuelta al juez ordinario conllevó efectos generales (Caso 10-18$\mathrm{CN}$ ), por lo que la segunda sentencia supone particular interés para nuestro análisis. De otro lado, se debe señalar que se trató de una votación compleja que dividió los criterios de los jueces constitucionales en ambos casos. Así, en las dos decisiones existieron votos salvados, esto es, que frente al voto de la mayoría de los miembros (cinco jueces), los votos salvados tanto para el caso 11-18 como para el 10-18, cuyo ponente fue el presidente de la Corte, concitaron la adhesión del resto de jueces (cuatro votos).

2. ANÁLISIS DEL CASO 11-18-CN, QUE PERMITE EL MATRIMONIO

CIVIL IGUALITARIO CON EFECTO INTER PARTES

\subsection{Hechos del caso}

La consulta de constitucionalidad, como ya se dijo más arriba, fue realizada por el Tribunal de la Sala Penal de la Corte Superior de Justicia de Pichincha, dentro de una acción de protección de derechos constitucionales, en la que preguntó si la Opinión Consultiva OC-24/17 de la Corte Interamericana de Derechos Humanos (Corte IDH), que reconoce el matrimonio de parejas del mismo sexo, es compatible con el artículo 67 de la Constitución, que establece que el matrimonio es entre hombre y mujer. La Corte Constitucional, en este sentido, analizó el valor jurídico de la opinión consultiva, interpretó la norma constitucional y estableció los efectos jurídicos de esta interpretación constitucional.

El 13 de abril de 2018, los señores E. Soria y R. Benalcázar solicitaron la celebración y la inscripción de su matrimonio en el Registro Civil; sin embargo, dicha entidad pública, con fecha 7 de mayo de 2018, negó tal inscripción, indicándoles a los interesados que el matrimonio en el ordenamiento jurídico ecuatoriano existe únicamente entre un hombre y una mujer. Posteriormente, al considerar vulnerados sus derechos, con fecha 9 de julio de 2018, los señores Soria y Benalcázar presentaron una acción de protección, en la que exigieron la aplicación de la citada Opinión Consultiva OC-24/17 
de la Corte IDH, que permite el matrimonio entre personas del mismo sexo. El 14 de agosto de 2018, el juez de la Unidad Judicial de Tránsito con sede en Quito, en sentencia, concluyó que "no existe vulneración de derecho constitucional alguno" y declaró improcedente la acción de protección propuesta por los accionantes, situación por la cual en la misma audiencia se presentó el recurso de apelación. Más adelante, el 18 de octubre de 2018, el Tribunal de la Sala Penal de la Corte Superior de Justicia de Pichincha, con motivo del conocimiento de la acción de protección por apelación, suspendió el procedimiento y remitió a la Corte Constitucional la consulta. Por sorteo de la causa, le correspondió la sustanciación al juez constitucional Ramiro Ávila. El 29 de marzo de 2019 tuvo lugar la audiencia pública en la que se escuchó a representantes de instituciones del Estado, a organizaciones de la sociedad civil, universidades y personas naturales, además de que el juez constitucional sustanciador recibió escritos de amicus curiae que le aportaron razones sobre cómo resolver la causa.

Con estos antecedentes, los tres problemas jurídicos formulados por la Corte se dirigen a responder a la pregunta de si la Opinión Consultiva OC-24/17 es un instrumento internacional de derechos humanos conforme lo reconoce la Constitución, directa e indirectamente aplicable en Ecuador; luego, a responder si el contenido de la opinión consultiva en cuestión, que reconoce el derecho al matrimonio de las parejas del mismo sexo, contradice el artículo 67 de la Constitución en el que se dispone que el matrimonio es entre un hombre y una mujer; para, finalmente, determinar, si es que la opinión consultiva es aplicable en el sistema jurídico ecuatoriano, cuáles son los efectos jurídicos respecto de los funcionarios públicos y los operadores judiciales.

Esto se resume en tres aspectos: a) la importancia del derecho internacional de los derechos humanos para el constitucionalismo ecuatoriano, b) que cualquier disposición normativa interna que trate de forma discriminatoria en cuanto al disfrute de derechos a las parejas del mismo sexo es contraria al derecho a la igualdad, y c) que se garanticen los derechos a la autonomía y al libre desarrollo de la personalidad conforme la Constitución de 2008.

\subsection{La importancia del derecho internacional de los derechos humanos para el constitucionalismo ecuatoriano}

Entre las características del modelo constitucional ecuatoriano se destaca la importancia que se le atribuye al derecho internacional de los derechos humanos, materializado por medio del bloque de constitucionalidad. En este sentido, el artículo 11, número 3, determina que los derechos y garantías establecidos en la Constitución, así como en los instrumentos internacionales de derechos humanos, serán de directa e inmediata aplicación por parte de todo funcionario público. Así también, el número 7 del referido artículo 11 señala que el reconocimiento de los derechos y garantías contemplados en 
la Constitución y en los instrumentos internacionales de derechos humanos no excluye los demás derechos derivados de la dignidad de las personas, comunidades, pueblos y nacionalidades. Por su parte, el artículo 417 prescribe que los tratados internacionales ratificados por Ecuador se sujetan a lo establecido en la Constitución, y que en el caso de los tratados e instrumentos internacionales de derechos humanos se aplicarán los principios pro homine, de no restricción de derechos, de aplicación directa y de cláusula abierta. De su lado, el artículo 426 determina que los jueces, autoridades administrativas y servidores públicos en general, aplicarán directamente las normas constitucionales, así como las previstas en los instrumentos internacionales de derechos humanos siempre que sean más favorables a las establecidas en la Constitución.

De ahí que, sobre la base de las disposiciones constitucionales anotadas más arriba, en el voto de mayoría del caso analizado, se advierte que para las fuentes de derechos en Ecuador se puede recurrir al texto constitucional y a los tratados y demás instrumentos internacionales. En ese sentido no cabría la distinción formulada entre tratados e instrumentos, en la medida en que todos los derechos reconocidos en instrumentos internacionales forman parten del ordenamiento jurídico ${ }^{4}$. A continuación la Corte Constitucional procede a argüir que la Opinión Consultiva OC-24/17, motivo de este caso, por medio de la cual se interpretan algunas disposiciones de la Convención Americana de Derechos Humanos (CADH), ya fue utilizada por la Corte ecuatoriana en un caso pasado. En efecto, la Corte Constitucional, en la Sentencia 184-18-SEP-CC, del 29 de mayo de 2018, en la página 58, señaló que la Opinión Consultiva OC-24/17 expedida por la Corte IDH se entiende adherida a la Constitución de conformidad con el artículo 426 CP y es de aplicación directa e inmediata, en tanto que su contenido sea más favorable para el ejercicio de los derechos. En definitiva, la opinión consultiva, a decir de la Corte Constitucional, forma parte de los instrumentos internacionales de derechos humanos, al tratarse de una interpretación legítima y auténtica de la CADH, por parte de la Corte IDH, y por tanto dicha opinión consultiva forma parte del bloque de constitucionalidad ${ }^{5}$.

En este orden de consideraciones, la Corte Constitucional sostiene que no existe contradicción entre la Opinión Consultiva 24/17 ${ }^{[6]}$ y el artículo 67 de la Constitución que establece que el matrimonio es la unión entre un hombre

4 Véase Ecuador. Corte Constitucional. Sentencia 11-18-CN, considerandos 29 y 30.

5 Véase Ecuador. Corte Constitucional. Sentencia 11-18-CN, considerando 39.

6 La opinión consultiva, en su parte resolutiva número ocho, determina: "De acuerdo a los artículos 1.1, 2, 11.2, 17 y 24 de la Convención es necesario que los Estados garanticen el acceso a todas las figuras ya existentes en los ordenamientos jurídicos internos, incluyendo el derecho al matrimonio, para asegurar la protección de todos los derechos de las familias conformadas por parejas del mismo sexo, sin discriminación con respecto a las que están constituidas por parejas heterosexuales". 
y una mujer ${ }^{7}$. En la medida en que afirma que se estaría ante una aparente tensión entre dos normas en vigor, la una que establece que el matrimonio es entre un hombre y una mujer, sobre la base de la Constitución y de la ley ${ }^{8}, \mathrm{y}$ la otra que reconoce el matrimonio entre personas del mismo sexo, a partir de la interpretación autorizada de la CADH, por parte de la Corte IDH, a través de la Opinión Consultiva OC-24/1 $7^{[9]}$. En este sentido, para superar esta aparente tensión de normas, la Corte acude a métodos de interpretación, así como a derechos constitucionales relacionados con el objeto de la consulta. Entre los métodos de interpretación aparecen el integral frente al literal, el evolutivo frente al estático, así como la importancia de la interpretación en clave pro ser humano. De otro lado, el énfasis se sitúa, como hemos dicho, en la relevancia que comporta el bloque de constitucionalidad para nuestro ordenamiento jurídico, así como en el derecho a la igualdad, al libre desarrollo de la personalidad o al derecho a la intimidad personal y familiar y el rol del Estado.

La importancia que suponen los métodos de interpretación aludidos por la Corte da cuenta de la intención del constituyente de superar una interpretación que se circunscriba a la individualidad literal de las disposiciones constitucionales, a favor de una interpretación que abraza la literalidad en clave integral a la luz de la maximización de los derechos constitucionales. En este sentido, el artículo 427 del texto constitucional señala que las normas se interpretan por el tenor literal que más se ajuste a la Constitución en su integralidad, y que en caso de duda se interpretará en el sentido que más favorezca la plena vigencia de los derechos, respetando la voluntad del constituyente. Método de interpretación constitucional que, en definitiva, persigue defender el programa de valores contenidos en el texto constitucional, en donde juegan un papel central para la protección de los derechos el bloque de constitucionalidad. Dicho bloque comprende, entre otras cosas, las opiniones consultivas emitidas por la Corte IDH respecto de la CADH.

\subsection{DERECHO A LA IGUALDAD}

Como cualquier ordenamiento constitucional contemporáneo, el ecuatoriano contempla el valor de la igualdad como principio, cuando sostiene que

$7 \quad$ El artículo 67 de la Constitución señala: "Se reconoce la familia en sus diversos tipos. El Estado la protegerá como núcleo fundamental de la sociedad y garantizará condiciones que favorezcan integralmente la consecución de sus fines. Éstas se constituirán por vínculos jurídicos o de hecho y se basarán en la igualdad de derechos y oportunidad de sus integrantes. El matrimonio es la unión entre hombre y mujer, se fundará en el libre consentimiento de las personas contrayentes y en la igualdad de derechos, obligaciones y capacidad legal".

8 El Código Civil, en su artículo 81, determina: "matrimonio es un contrato solemne por el cual un hombre y una mujer se unen con el fin de vivir juntos, procrear y auxiliarse mutuamente"; por su parte, la Ley Orgánica de Gestión de la Identidad y Datos Civiles, en el artículo 52 , señala: “... el matrimonio es la unión entre un hombre y una mujer...”.

9 Véase Ecuador. Corte Constitucional. Sentencia 11-18-CN, considerando 48. 
todas las personas son iguales y gozarán de los mismos derechos, deberes y oportunidades (art. 11, n. ${ }^{\circ}$ 2), y se contempla también como derecho cuando prescribe que se garantiza a todas las personas el derecho a la igualdad formal, así como a la igualdad material y a la no discriminación (art. 66, n..$^{\circ}$ 4). En este sentido, la igualdad como principio sería entendida, siguiendo a Dworkin, en el sentido de que todas las personas deben ser tratadas con la misma consideración y respeto por parte del poder público, como consecuencia de lo cual ciertos tratos han de ser atribuidos a todos igualmente cuando no haya base para establecer diferencias de tratamiento ${ }^{10}$. La igualdad como derecho supone, por otra parte, el derecho subjetivo de las personas, pero también alude a una dimensión de tipo objetivo que obliga al Estado a tratar igual a quienes están en igual condición; en suma, el derecho a la igualdad afirma que cuando no hay diferencias relevantes el tratamiento debe ser igual, y que cuando hay diferencias relevantes el tratamiento debe ser diferenciado ${ }^{11}$.

En este orden de consideraciones, la interpretación restrictiva y aislada del artículo 67 del texto constitucional ecuatoriano, en el sentido de que el matrimonio es una facultad exclusiva de las parejas heterosexuales, iría en contravía del derecho a la igualdad y no discriminación garantizado a todas las personas. Así, tenemos que la Corte Constitucional discute si la diferencia realizada, fundada en una categoría sospechosa, es razonable o discriminatoria a la luz de los fines constitucionales ${ }^{12}$. De ahí que lo que hace la Corte sea analizar la interpretación literal y asistemática del artículo 67, a partir de los presupuestos establecidos en el artículo 11, número 2 de la misma Constitución, en cuanto a la configuración del trato discriminatorio; para concluir que, desde una interpretación sistemática y favorable a la progresividad de derechos, la interpretación no integral y restringida no persigue un fin constitucionalmente válido. En este sentido, analiza las razones y fines extralegales, legales y constitucionales de una comprensión del matrimonio como derecho exclusivo de las personas heterosexuales. Así, respecto de la distinción entre parejas de diferente sexo y parejas del mismo sexo, para reservar el acceso al derecho al matrimonio solamente a las primeras, dice la Corte que "una medida restrictiva a los derechos, del tipo excluir del ejercicio de derechos a un grupo de personas, estaría prima facie prohibida por la Constitución" ${ }^{13}$. En este orden de ideas, la Corte advierte que los fines perseguidos por consideraciones extralegales que se fundan en convicciones religiosas o sociales convencionales discriminatorias no constituyen razones

10 AÑón. M. Los principios y valores que guían los derechos: igualdad. En De LucAs, J. y Rodríguez, J. (coords.), Derechos humanos y Constitución. Valencia: Tirant lo Blanch, 2018, 105.

11 Ibid., p. 106.

12 Véase Ecuador. Corte Constitucional. Sentencia 11-18-CN, considerando 77.

13 Véase ibid., considerando 103. 
justificadas para no permitir el acceso al matrimonio a las parejas del mismo sexo $^{14}$. Del mismo modo, para la Corte los fines legales, según lo contemplado por las disposiciones del Código Civil y de la Ley de Gestión de la Identidad y Datos Civiles, no suponen necesariamente fines constitucionales, ya que estos últimos no pueden ser entendidos de manera excluyente, y por el contrario la Constitución se abre a las realidades cambiantes de una comunidad ${ }^{15}$. En este sentido se comprendería que el fin constitucionalmente válido abraza la noción más amplia posible del derecho a constituir una familia por medio del matrimonio, y en consecuencia no existe fin constitucional alguno para excluir del matrimonio a las parejas del mismo $\operatorname{sexo}^{16}$.

El derecho a la igualdad y no discriminación, respecto de la capacidad de contraer matrimonio por parte de las parejas del mismo sexo, se encuentra en íntima conexión con el ámbito de las relaciones familiares, la dignidad de la persona y el libre desarrollo de la personalidad. De ahí que la normativa y la jurisprudencia de realidades comparadas hayan ido profundizando en la realización de los derechos de todas las personas, adaptándose a las demandas sociales y culturales de cada momento ${ }^{17}$.

Seguidamente abordaremos el derecho al libre desarrollo de la personalidad como expresión del derecho a la autonomía.

\subsection{Libre desarrollo de la personalidad}

El libre desarrollo de la personalidad concretiza el ideal de autonomía individual, el cual, como anota la Corte Constitucional, implica la facultad que tienen las personas para autodeterminarse, decidir sus propios fines y establecer los medios para conseguirlos, siempre que se respeten los derechos de otras personas ${ }^{18}$.

En este orden de ideas, privar del derecho de casarse a las parejas del mismo sexo, a partir del ideal de que existe un solo modelo de familia, defendido por el Estado, que se edifica sobre la base del matrimonio entre personas de distinto sexo, supone una violación indebida de la autonomía de las personas, concretado en la elección de un libre plan de vida ${ }^{19}$. No se debe perder de vista que las personas, al compartir la cualidad de seres racionales, son

14 Véase ibid., considerando 95.

15 Véase ibid., considerando 99.

16 Véase ibid., considerando 109.

17 Picontó, T. Familia, matrimonio y derecho a la libre opción de la sexualidad. En DE LuCAs, J. y RodRíGuez, J. (coords.), Derechos humanos y Constitución. Valencia: Tirant lo Blanch, 2018, 516-517.

18 Véase Ecuador. Corte Constitucional. Sentencia 11-18-CN, considerando 167.

19 La decisión de contraer matrimonio es un asunto de la esfera privada, que tiene que ver con el plan de vida de un individuo, de manera que el Estado solo puede proscribir aquellas acciones que afecten objetivamente a terceros. Véase ibid., considerando 180. 
capaces de diseñar y poner en marcha su propio plan de vida sin interferencia estatal o de otros individuos, siempre y cuando dichos planes no afecten la autonomía de terceros ${ }^{20}$. La Corte, en este sentido, señala que existen derechos inclusivos, los cuales deben propender a su universalización, en la medida en que su expansión implica mayor dignificación de las personas, como ocurre con los derechos a la educación o a la salud, que permiten un libre desarrollo de la personalidad ${ }^{21}$. Así, la interpretación del matrimonio como un derecho exclusivo de parejas heterosexuales aparece como una limitación al libre desarrollo de la personalidad, así como al derecho a constituir una familia.

Finalmente, sobre la base de las consideraciones realizadas, la Corte Constitucional respecto del caso decidió que la Opinión Consultiva OC24/17 forma parte del bloque de constitucionalidad para reconocer derechos en Ecuador. Asimismo, la Corte estableció que no existe tensión entre el artículo 67 de la Constitución, que señala que el matrimonio es entre un hombre y una mujer, y el derecho convencional; en este sentido, aboga es por la complementariedad. Así, por la vía de la interpretación más favorable de derechos, el matrimonio heterosexual se entiende complementado con la posibilidad de igual acceso al derecho al matrimonio de las parejas del mismo sexo. Por lo tanto, la Corte Constitucional dispone que el tribunal consultante interprete el sistema normativo a la luz de esta sentencia y ordene al Registro Civil que se inscriba el matrimonio entre los accionantes. Sin que para ello se precise de reformas previas a la Constitución (art. 67), al Código Civil (art. 81) o a la Ley Orgánica de Gestión de Identidad y Datos Civiles (art. 52). Cuestión esta última que difiere respecto a lo decidido por la siguiente sentencia analizada (10-18-CN), que además de comportar efectos generales, no solo inter partes, declara la constitucionalidad condicionada de los artículos legales y exhorta a la Asamblea Nacional a adecuar la normativa al bloque de constitucionalidad.

\section{ANÁLISIS DEL CASO 10-18-CN, QUE PERMITE EL MATRIMONIO CIVIL IGUALITARIO CON EFECTOS GENERALES}

\subsection{Hechos del caso}

La Corte Constitucional de Ecuador, con cinco de nueve votos, luego de un intenso debate sobre la interpretación de la Constitución, la aplicación directa de los derechos y el rol de los instrumentos internacionales de derechos humanos, vía consulta de norma, expidió una sentencia de control abstracto

20 SABA, R. Introducción. Matrimonio, autonomía e igualdad. En Alterio, M. y Niembro, R. (coords.), La Suprema Corte y el matrimonio igualitario en México. México, D.F.: unAm, 2017,15 .

21 Véase Ecuador. Corte Constitucional. Sentencia 11-18-CN, considerando 173. 
de constitucionalidad modulando el contenido de los artículos 81 del Código Civil y 52 de la Ley Orgánica de Gestión de la Identidad Datos Civiles (LOGIDC), que reconocían el matrimonio civil como la unión entre "un hombre y una mujer", resolvió incluir en la citada norma a parejas del mismo sexo; y ello sin restricciones basadas en la orientación sexual o la obligación de "procrear", como prescribía el Código Civil. En efecto, las disposiciones jurídicas constitucionalmente moduladas, ahora vigentes, reconocen:

[CC] Art. 81. El matrimonio es un contrato solemne por el cual dos personas se unen con el fin de vivir juntos y auxiliarse mutuamente.

[LOGIDC] Art. 52. La autoridad ante quien se celebra el matrimonio. El matrimonio es la unión entre dos personas y se celebra e inscribe ante la Dirección General de Registro Civil, Identificación y Cedulación. Fuera del territorio ecuatoriano, se celebra e inscribe ante el agente diplomático consular, si al menos uno de los contrayentes es ecuatoriano.

En ese sentido, lo que interesa en este estudio es saber cómo llegó el caso y, a partir de este, cómo la Corte Constitucional reconoció el matrimonio entre personas de orientación sexual diversa en Ecuador. En el año 2017, la Dirección General de Registro Civil (DGRC) negó a los accionantes R. Salazar y C. Verdezoto la posibilidad de contraer matrimonio civil, basada en una comprensión literal y formalista de la Constitución y del Código Civil que en sus artículos 67 y 81 regulaban el matrimonio exclusivamente para parejas heterosexuales, y en su lugar norma la unión de hecho como un medio para legalizar las relaciones entre parejas homosexuales, conforme lo previsto en el artículo 68 de la Constitución.

Este hecho impulsó a Salazar y Verdezoto, apoyados por organizaciones sociales LGTBI y ONG, a presentar una acción de protección contra la DGRC, por trato discriminatorio y por desconocer la Opinión Consultiva 24/17 de la Corte IDH. Un año después, en agosto de 2018, la jueza de primer nivel, Gabriela Lemos, siguiendo lo previsto en el artículo 428 de la Constitución y las exigencias de la Sentencia constitucional 001-13-sCN-CC, que obliga a los jueces del país a consultar a la Corte Constitucional si en el caso concreto se descubre cualquier incompatibilidad de la ley con la Constitución, acudió ante ella, y, según se señaló al inicio de este artículo, como consecuencia de ello se adoptó la citada decisión, que eliminó cualquier vestigio de control difuso en Ecuador. En efecto, la jueza remitió el proceso en consulta a la Corte Constitucional, con sustento en la prohibición de trato discriminatorio y la aplicación directa de la Opinión Consultiva 24/17, la cual se pronunció sobre la identidad de género y no discriminación de las parejas homosexuales; instrumento que, a su vez, interpretó los artículos 1, 24 y 17.2 de la CADH. La Corte IDH orientó su opinión para que todos los países miembros de la 
OEA, hayan o no ratificado la competencia contenciosa de la Corte IDH, se abstengan de establecer instituciones jurídicas diferentes para situaciones jurídicas similares, como es el caso del matrimonio que puede ocurrir tanto entre parejas homosexuales como heterosexuales, considerando que de acuerdo a un escrutinio estricto de igualdad, las diferencias basadas en las orientaciones sexuales de las personas son un acto discriminatorio y, por tanto, incompatible con la Convención ${ }^{22}$.

En 2019 llegó el caso a la Corte Constitucional, correspondiendo la sustanciación y ponencia del mismo al juez constitucional Alí Lozada, quien en su ponencia planteó problemas jurídico-constitucionales teórico-prácticos distintos en parte a los propuestos en el Caso 11-18-CN, que sobre el mismo tema resolvió la Corte, como ya se expuso. En el Caso 11-18 el juez ponente, Ramiro Ávila, concentró sus esfuerzos hermenéuticos e interpretativos en definir el valor de los instrumentos internacionales cuando reconocen derechos más favorables a las personas que el ordenamiento interno; en cambio, la sentencia del Caso 10-18-CN, del juez Lozada, propone analizar el caso a la luz de la interpretación constitucional y definir el rol de los jueces frente a la discrecionalidad del Parlamento, así como traer al análisis del caso la doctrina de la democracia deliberativa, la protección del núcleo esencial de los derechos y el test de ponderación, inclinando el peso de la balanza al reconocimiento de los derechos de las parejas del mismo sexo por sobre el principio democrático.

En el Caso 10-18-CN el punto de partida, de acuerdo con el canon de la argumentación, es el problema jurídico planteado en términos de control abstracto y sobre el rol del legislador dentro del juego argumentativo, relegando para la parte final de la sentencia el rol de los instrumentos internacionales de derechos humanos, que plantea si la Corte Constitucional debe declarar inconstitucionales los artículos 81 del Código Civil y 52 de la LOGIDC; de dicho cuestionamiento, a su vez, se desprenden dos problemas específicos, a saber: "¿en qué medida la Constitución obliga, prohíbe o permite al legislador democrático [...] instituir el matrimonio entre personas del mismo sexo? y ¿qué debe decidir la Corte Constitucional respecto de la inconstitucionalidad de la norma cuestionada?"23. Las respuestas coinciden en que las normas analizadas son inconstitucionales, y en la necesidad de reconocer el derecho a la igualdad, al libre desarrollo de la personalidad y el derecho al matrimonio entre parejas del mismo sexo, señalando que es necesaria la modulación sustractiva de las normas del Código Civil y de la LOGIDC para lograr el

22 Corte IDH. Opinión Consultiva OC-24/17. Identidad de género, e igualdad y no discriminación a parejas del mismo sexo. San José de Costa Rica. 24 de noviembre de 2017. Serie A n. ${ }^{\circ} 24$.

23 Véase Ecuador. Corte Constitucional. Sentencia 010-18-CC, considerandos 19-24. 
reconocimiento del matrimonio en términos de igualdad. A continuación se pasa a analizar los principales puntos críticos de la decisión constitucional.

\subsection{La interpretación constitucional: la literalidad e intencionalidad frente a la comprensión integral y dinámica de la Constitución}

La Corte, para reconocer la situación jurídica del matrimonio entre personas del mismo sexo, optó por la interpretación jurídica integral y dinámica de la Constitución, frente a las claras situaciones jurídicas y sociales de discriminación a las que se ven sometidas las parejas homosexuales debido a la falta de regulación y protección de este derecho.

En este sentido, se puede leer en el voto de mayoría y de minoría que, dependiendo de la opción interpretativa que se aplique al caso, la respuesta jurídica será distinta. El voto de mayoría interpreta el derecho desde un punto de vista axiológico e integral que permite comprender a la Constitución como un tejido axiológico de derechos, valores y principios, que proscriben toda forma de discriminación entre parejas del mismo sexo. De otro lado, en el voto de minoría, el literalismo y el formalismo jurídico impedirían la citada posibilidad jurídica, considerando que no se puede ir más allá de la letra de la Constitución y la ley, que reconocen al matrimonio como la unión entre un hombre y una mujer, y que si se busca ampliar esta posibilidad jurídica debe hacerse mediante una reforma que modifique el artículo 67 de la Constitución de Ecuador.

Es por ello que se puede advertir, en la sentencia analizada, la preocupación del juez constitucional sobre la cultura jurídica ecuatoriana, fuertemente formalista, que limita el campo de aplicación del derecho a la exégesis de las normas, dotando de significados reduccionistas a todo el derecho ${ }^{24}$. De ahí que los argumentos literal e intencional, guiados por la deferencia a la amplia discrecionalidad del constituyente y del legislador, al configurar la Constitución y las leyes, serían determinantes para afirmar que el ordenamiento jurídico ecuatoriano "no confiere poder jurídico a las personas del mismo sexo para contraer matrimonio"25.

En este orden de consideraciones, para aclarar este punto, la interpretación de la Constitución se reduce a la intención del constituyente, y no puede ir más allá de la interpretación literal, previendo únicamente que el matrimonio es un vínculo entre un hombre y una mujer; en consecuencia, desde esa posibilidad hermenéutica, el matrimonio homosexual está prohibido. Es así como el argumento intencionalista constituye una deferencia al autor del

24 Véase ibid., considerando 30.

25 Véase ibid., considerando 31. 
artículo 67 de la Constitución, de donde se extrae como significado el privar o prohibir a las parejas del mismo sexo el contraer matrimonio ${ }^{26}$.

$\mathrm{Al}$ respecto, la Corte considera que existen debilidades argumentativas en estas aseveraciones, mas no cuestiona el valor de la democracia, pues entender que la regulación constitucional del artículo 67 de la Constitución trae implícita una prohibición e intenta, a partir de esa lectura, afirmar que la voluntad del poder constituyente fue que se prohíban ciertas instituciones resulta, a decir del alto tribunal, difícil de sostener. En este sentido, para la Corte es más adecuado, a partir del tejido axiológico, sostener que la no regulación del matrimonio entre parejas del mismo sexo en la Constitución es una laguna axiológica, que no implica lingüísticamente reconocer que se encuentra prohibida esta posibilidad jurídica.

Así, la cultura jurídica formalista pretende imponer que solo puede existir el matrimonio heterosexual, y desde esa óptica no existe una forma de comprender la realidad o la interpretación del derecho que no sea desde lo que está escrito en la ley. Por el contrario, para la Corte, se debe interpretar el artículo 67 de la Constitución, inserto en un entramado axiológico de valores y principios que permiten comprender el matrimonio dentro del contexto amplio de derechos como la autonomía, el libre desarrollo de la personalidad, la igualdad y la dignidad que rodea la realidad de quienes son excluidos por las instituciones jurídicas y sociales.

En este orden de ideas, la Corte propone cambiar la forma de aplicar el derecho constitucional, irradiando lo razonable de la decisión a la construcción de un derecho que vaya más allá de la letra de la ley y, en su lugar, dé respuestas jurídicas razonablemente justas a una sociedad plural con un Estado laico.

Posteriormente, en el contexto de descubrimiento, para salir de la interpretación literalista e intencionalista de la Constitución, revisa los valores y principios sociales que subyacen a la hipótesis de prohibir o permitir el matrimonio entre personas del mismo sexo, en el siguiente orden.

Ante este diverso entramado de argumentos sobre el matrimonio entre parejas del mismo sexo la Corte considera importante partir del significado de Constitución ${ }^{27}$, dado por el artículo 1 del texto constitucional que define al Estado como de derechos y justicia, base sobre la cual se elabora una respuesta jurídica integral y dinámica, que protege los derechos de las parejas del mismo sexo en pie de igualdad, así como su igual dignidad humana. Aspectos que de forma permanente darán razones de peso para interpretar la Constitución en relación con los derechos de las parejas diversas.

26 Herrera, A. Estudio introductorio. En Ely, J. y Slagstad, R., Constitucionalismo y democracia. México, D.F.: Fondo de Cultura Económica, 2001, 8.

27 Véase ibid., considerando 37. 
TABLA 1. ARGUMENTOS A FAVOR Y EN CONTRA DEL MATRIMONIO IGUALITARIO

\begin{tabular}{|c|c|c|}
\hline Criterio & $\begin{array}{l}\text { Argumentos contra el } \\
\text { matrimonio igualitario }\end{array}$ & $\begin{array}{c}\text { Argumentos a favor } \\
\text { del matrimonio igualitario }\end{array}$ \\
\hline $\begin{array}{l}\text { Interpretación } \\
\text { del derecho }\end{array}$ & $\begin{array}{l}\text { - Literal: el artículo } 67 \text { prevé el } \\
\text { matrimonio entre un hombre y una } \\
\text { mujer. } \\
\text { - Intencionalista: el constituyente, } \\
\text { al no regular el matrimonio } \\
\text { igualitario, lo prohibió. }\end{array}$ & $\begin{array}{l}\text { - Interpretación integral. } \\
\text { - Interpretación dinámica. }\end{array}$ \\
\hline Constitucional & $\begin{array}{l}\text { - Derecho de los padres a educar a } \\
\text { los hijos en la heterosexualidad. }\end{array}$ & $\begin{array}{l}\text { - El valor de la laicidad y la ética pública. } \\
\text { - El buen vivir en un contexto plural. } \\
\text { - El derecho a los diversos tipos de familia. } \\
\text { - El derecho al matrimonio en el libre } \\
\text { desarrollo de la personalidad. } \\
\text { - La libertad de conciencia e intimidad. }\end{array}$ \\
\hline Religioso $^{a}$ & $\begin{array}{l}\text { - Alianza matrimonial como } \\
\text { sacramento, matrimonio en el plan } \\
\text { de Dios, y encíclica Lumen fidei. }\end{array}$ & - La libertad religiosa. \\
\hline Prejuicio $^{b}$ & $\begin{array}{l}\text { - La esterilidad reproductiva de las } \\
\text { parejas del mismo sexo. } \\
\text { La homosexualidad como desorden } \\
\text { psiquiátrico y moral. }\end{array}$ & - No amerita análisis jurídico. \\
\hline Social $^{c}$ & $\begin{array}{l}\text { - La inadecuación de las uniones } \\
\text { homosexuales al modelo tradicional } \\
\text { de matrimonio. } \\
\text { La esterilidad de las parejas del } \\
\text { mismo sexo. }\end{array}$ & $\begin{array}{l}\text { - Respeto de las posturas personales: } \\
\text { autonomía de la voluntad y libre desarrollo } \\
\text { de la personalidad. }\end{array}$ \\
\hline \multicolumn{3}{|c|}{$\begin{array}{l}\text { Conclusión intermedia: los argumentos literalitas e intencionalista sustentan levemente la deferencia } \\
\text { al legislador. }\end{array}$} \\
\hline
\end{tabular}

${ }^{a}$ Ecuador. Corte Constitucional. Sentencia 010-19-CN, párr. 37: "La inadecuación de las uniones homosexuales al modelo tradicional de matrimonio es un argumento que propone que el matrimonio civil igualitario es una amenaza a las tradiciones que se desprenden del matrimonio civil reconocido en el Ecuador desde 1903; no de forma clara, como en otras partes de la sentencia, se sostiene que aceptar esto permitiría que se establezcan restricciones basadas en las tradiciones a los derechos fundamentales".

${ }^{b}$ Véanse los considerandos 38 y 39 de la sentencia 010-18-CN de la Corte Constitucional de Ecuador: "La homosexualidad como desorden psiquiátrico, a la que haría alusión Esthela Velasco en su intervención oral como interesada en el tema, al contraponerlo a la desclasificación de enfermedades realizada por [...] se consideró que no existe base racional para creer que las personas homosexuales son enfermas mentales, en tanto ningún análisis podría extraerse de este prejuicio. iv) La homosexualidad como desorden moral, sería entender esta opción personal como un atentado a las buenas costumbres que el Asambleísta Constituyente, esta aseveración al considerarla cercana a la visión de la Iglesia Católica, en un contexto en el cual al rededor del $80 \%$ de habitantes son católicos, delinea una concesión que tiene varios fragmentos: a) alianza matrimonial entre hombre y mujer constituye un sacramento, b) matrimonio en el plan de Dios, constituye un mandato divino entre el hombre y la mujer; c) la carta encíclica Lumen".

${ }^{c}$ Véase ibid., considerando 36. La esterilidad reproductiva de las parejas del mismo sexo impediría la realización de la familia, argumento que se disuelve frente al reconocimiento constitucional de los varios tipos de familia y al aclarar que el matrimonio no es una institución creada con fines de crecimiento demográfico.

Fuente: elaboración propia. 
En cuanto al debate nacional, la resolución de un caso difícil y de grandes dimensiones tiene pretensiones de cambiar algunos componentes sociales, como, en el caso que nos ocupa, el que se refiere a pasar del matrimonio tradicional a uno igualitario, lo que no solo concierne a la cultura jurídica sino a la sociedad en su conjunto. Por ello es posible que en un futuro no tan lejano pueda producirse una respuesta, política y jurídica, desde una visión conservadora, que a través de diferentes estrategias intente volver al matrimonio heterosexual como única opción ${ }^{28}$, yendo así más allá del llamado de tolerancia y a la construcción hermenéutica igualitaria que realiza la Corte Constitucional.

Por lo expuesto, para el caso de Ecuador este tópico va mucho más allá del equilibro de principios morales o de la elección de un método de interpretación constitucional; se trata, pues, de dar cuenta del nivel de tolerancia y aceptación que tenemos como ciudadanos para reconocer y respetar los derechos de las minorías. En consecuencia, es el inicio para establecer un compromiso serio con la Constitución y los significados otorgados, en este caso por la Corte Constitucional, a los derechos, sin que ello suponga que desaparezcan los desacuerdos sobre el tema.

\subsection{Derecho a la igualdad y los tipos de democracia aplicados a la sentencia del matrimonio entre parejas del mismo sexo}

El derecho a la igualdad es una parte central de la sentencia en el Caso 10-18-CN, en el contexto del reconocimiento del derecho constitucional al matrimonio de parejas del mismo sexo. Así, los legisladores habrían entrado en mora legislativa al no proteger a las parejas homosexuales y, en consecuencia, condenarlas a una situación jurídica y social de discriminación estigmatizante, asegura la Corte.

Sobre este punto, la decisión complementa temas opuestos o contradictorios, corriendo el riesgo de acumular doctrinas que no contribuyan a la solidez de la argumentación, sea por su naturaleza conceptual o por su funcionamiento práctico, como ocurre con el hecho de configurar una tríada de valores que intentan funcionar en la sentencia de manera armónica y no contrapuesta, como son los de democracia representativa, democracia deliberativa y derecho constitucional a la igualdad.

\subsubsection{El rol de la democracia en el caso del matrimonio igualitario}

Es deber del legislador regular y proteger los derechos fundamentales a través de la expedición de la ley, según la sentencia, sea que estos derechos se en-

28 Post, R. y Reva, S. Constitucionalismo democrático. Por una reconciliación entre Constitución y pueblo. Buenos Aires: Siglo xxI Editores, 2013, 65. 
cuentren reconocidos en la Constitución o en los instrumentos internacionales de derechos humanos; bajo esta consideración, los representantes del pueblo tenían el deber de legislar en materia de matrimonio igualitario para cumplir con las exigencias del principio de igualdad y el principio democrático ${ }^{29}$.

La Corte, en la decisión, manifiesta que el artículo 81 del Código Civil guardaría coherencia con el artículo 67 de la Constitución que regula el matrimonio heterosexual en Ecuador, y en este sentido el respeto a la disposición legal constituiría una deferencia al legislador. Sin embargo, la Corte también advierte que mantener normas con criterios sospechosos en el ordenamiento jurídico, como la distinción basada en la orientación sexual, para impedir el acceso a la institución civil del matrimonio, no guarda coherencia con el tejido valorativo que encierra el texto constitucional en su conjunto.

En este orden de ideas, la Corte considera que la presunción de constitucionalidad de las normas, conforme el principio pro legislatore previsto en el artículo 76.1 de la Ley Orgánica de Garantías Jurisdiccionales y Control Constitucional (LOGJCC), refuerza el principio democrático, en la medida en que para la declaratoria de inconstitucionalidad de una norma se exige que dicha afirmación supere la duda razonable para poder declarar que una disposición jurídica es contraria a la Constitución ${ }^{30}$. Por esa razón, la sentencia considera que, al sopesar el principio democrático, comprendido como una deferencia al legislador, con el derecho al matrimonio entre parejas del mismo sexo, el principio democrático debe ceder ante el derecho a la igualdad formal y material, señalando que era deber del legislador regular el matrimonio entre parejas del mismo sexo.

Inmediatamente después, la sentencia ingresa en un tema de compleja resolución como es el de la democracia deliberativa, señalando:

[E]l valor de la ley no se radica en la autoridad formal del legislador, sino también en el hecho de que ella deba ser producto de una deliberación, o sea, de un debate basado en la confrontación de razones provenientes de todos los interesados. La existencia de dicho debate, según la Constitución, ha de proyectarse hacia dentro de la Asamblea Nacional, con la exigencia de que un proyecto de ley debe ser sometido a dos debates (art. 137, inciso primero CRE), pero también por fuera de ella, con la previsión de que las personas "que tengan intereses en la aprobación de [un] proyecto de ley, o que sus derechos puedan ser afectados por su expedición, p[uedan] acudir ante la comisión y exponer sus argumentos" (art. 137, segundo inciso) ${ }^{31}$.

Para reforzar su punto, la Corte toma como referencia la Sentencia 018-18-SIN$\mathrm{CC}$, que declaró la inconstitucionalidad de la enmienda constitucional de

\footnotetext{
29 Véase Ecuador. Corte Constitucional. Sentencia 010-18-CN, considerandos 58 y 59.

30 Véase ibid., considerando 59.

31 Véase ibid., considerando 59.
} 
2015, bajo el supuesto de que la Asamblea trató los temas de la reforma en bloque y no artículo por artículo, lo que a criterio del máximo tribunal causó una violación al principio de democracia deliberativa. La Corte, al seguir ese precedente, da señales de que ciertos aspectos de una deliberación se tornan en un presupuesto para ejecutar el control de constitucionalidad de las normas, y que incumplirlo causaría su inconstitucionalidad. Situación que, a nuestro juicio, debe ser analizada con mayor detalle.

En suma, la Corte, en sus sentencias 018-18-SIN-CC y 010-19-CN, trata el tema de la deliberación como una especie de requisito aplicable al proceso de enmienda constitucional y de creación de una ley, mas no a la construcción de un sistema de democracia deliberativa ${ }^{32}$. Lo anterior, entendiendo por modelo democrático deliberativo al sistema de decisiones participativas en donde prima el debate en igualdad de condiciones entre gobernantes y gobernados, asumiendo que el autogobierno colectivo puede seguir la construcción de sus propias decisiones, y que estos procesos sean aplicables para la creación de una ley o de una sentencia, como ocurriría en la deliberación. El sistema democrático ecuatoriano, con graves problemas de institucionalidad, si bien con ciertos niveles de participación, estaría lejos de constituirse en un modelo deliberativo.

Un sistema deliberativo, como sostiene Hübner Mendes, requiere al menos de los siguientes presupuestos: a) las decisiones deben ser realizadas por la colectividad y causar efectos directos en quienes deliberan; b) la solución a un problema no es un fin en sí mismo de la deliberación, podrían plantearse nuevas respuestas y soluciones; c) el razonamiento práctico y la justificación son la forma como se podrán ejercer los debates; d) la imparcialidad de los participantes en el debate debe ser la constante en los debates a menos que se busque el bien común; e) la deliberación abre la posibilidad de revisar las posturas de los participantes para lograr amplios consensos éticos; f) en todo momento se hará presente la ética, entendida como el respeto a las opiniones de los demás, y g) los comités políticos deberán ser inclusivos, empáticos y respetuosos de todos los puntos de vista ${ }^{33}$. La construcción participativa y dialógica de las decisiones políticas debe ser respetada por todos para evitar su incumplimiento y la suplantación con decisiones autoritarias. Finalmente, no cuestiona la autoridad coercitiva, que en última instancia le da un papel al Estado en la protección de los ciudadanos.

Las cortes o tribunales constitucionales, por su lado, poseen un rol de terceros imparciales frente a las partes y resguardan la protección de la Constitución frente a los demás poderes. En este sentido existen algunos espacios en los cuales las cortes se han propuesto realizar prácticas deliberativas, a

32 HüBner Mendes, C. Constitutional Courts and Deliberative Democracy. Oxford: Oxford University Press, 2015, 14.

33 Ibid., 14. 
través de figuras como los amicus curiae en las audiencias públicas. Sin duda, la implementación de lógicas deliberativas dentro del control judicial de constitucionalidad es un tema de gran relevancia, siendo necesario al respecto establecer mecanismos que fomenten el diálogo de los ciudadanos posiblemente afectados con una determinada normativa, así como del poder legislativo con la Corte. Dentro de estas coordenadas, en un tema como el matrimonio civil igualitario, no cabe duda que los debates ciudadanos serían muy diferentes a los que ocurren dentro de las paredes de la Corte, órgano último que posee una alta conciencia sobre los valores plurales y laicos de una República, protegiendo en tal sentido los derechos de las minorías frente a las decisiones de las mayorías. Es claro que en una democracia la Constitución funciona como un límite a la regla de la mayoría, pero cuando esos límites no están claros les corresponde a los jueces imponerlos desde su posición institucional. Lo que estaría en juego, de acá en adelante, es la construcción de condiciones para que se desarrolle una Corte para una democracia deliberativa, que, de un lado, evite el abuso de los legisladores, y, del otro, el gobierno de los jueces.

\subsubsection{El derecho a la igualdad}

El derecho a la igualdad formal y material desarrollado en la sentencia del Caso 010-19-CN contribuye a la corrección de las desigualdades basadas en criterios sospechosos, como el sexo, y mitiga el sufrimiento de las personas homosexuales. Bajo estos criterios, la decisión constitucional materializó el derecho al matrimonio de parejas del mismos sexo, protegiendo los derechos a la igualdad, al libre desarrollo de la personalidad, a la identidad personal y a la familia ${ }^{34}$.

La jurisprudencia desarrollada entre los años cuarenta y setenta por parte de la Corte Suprema de Estados Unidos constituye un notable aporte al constitucionalismo contemporáneo, con el establecimiento del test o escrutinio de igualdad, que permite decidir acerca de las distinciones que el Estado realiza entre personas, sugiriendo que las diferencias basadas en el color de piel, la nacionalidad o el sexo serán consideradas inconstitucionales ${ }^{35}$. Una excepción a ese criterio se dio con la decisión del caso Repetto, en donde se estableció que el Estado podrá justificar única y exclusivamente el criterio de distinción, por razones sospechosas, cuando sea por una situación de urgencia o excepcionalidad ${ }^{36}$.

34 Lozada, A. y Ricaurte C. Manual de argumentación jurídica. Quito: CEDeC y Corte Constitucional, 2013, 45.

35 SABA, R. Más allá de la igualdad formal ante la ley. ¿Qué les debe el Estado a los grupos desaventajados? Buenos Aires: Siglo XxI Editores, 2016, 83.

36 Tushnet, M. Constitucionalismo y judicial review. Lima: Palestra, 2013, 149-170. 
El test para el escrutinio estricto de igualdad implica que una persona que ha sido víctima de discriminación goza de la prerrogativa de no tener que argumentar o demostrar que ha sido violado su derecho a la igualdad, pues será el Estado quien deba demostrar que no ha discriminado, en casos de tratos diferenciados fundados en categorías sospechosas ${ }^{37}$.

Respecto del rol del derecho a la igualdad como medio para corregir las desigualdades en el control de constitucionalidad, Ariel Dulitzky sostiene que el escrutinio estricto de igualdad está relacionado con los catálogos que se denominan de discriminación, sirven para evaluar la convencionalidad o constitucionalidad de una norma, a su vez es un plus de la objetividad y razonabilidad de las decisiones, en efecto el trato basado en categorías sospechosas a priori considera es irrazonable. A la vez, señala que producto de estas categorías de protección surgen dos efectos: 1) las categorías prohibidas de alcance simétrico, como cuando se usa para restringir derechos o crear ventajas exageradas sobre otros grupos, por ejemplo, la categoría de sexo para darles ventajas a los varones sobre las mujeres; y 2) las categorías de acciones afirmativas, en donde esos criterios obran como impedimentos para que los grupos alcancen una igualdad de trato ${ }^{38}$, así como establece el principio de igualdad reconocido en el artículo 11. 2 de la Constitución de la República del Ecuador.

Sobre el derecho a la igualdad, la Corte IDH, en sus opiniones consultivas OC-4/84 $4^{[39]}$, OC-18/03 $3^{[40]}$ y OC-24/17 $7^{[41]}$, generó criterios interpretativos de los artículos 1 y 2 de la CADH, señalando que las categorías de la igualdad deben protegerse desde la condición del grupo que sufre la discriminación, el acceso a la justicia de la mujeres víctimas de violencia y reconoció que el trato diferenciado por el Estado al crear instituciones distintas para parejas del mismo sexo, constituyen comportamientos discriminatorios, respectivamente. Constituyen un avance en el desarrollo de este derecho y en la reafirmación de la prohibición de discriminación sustentada en categorías que se presu-

37 SABA. Más allá de la igualdad formal ante la ley, cit., 84.

38 Dulitzeky, A. Principio de igualdad y no discriminación. Claroscuros de la jurisprudencia interamericana. En Anuario de Derechos Humanos. 3, 2007, 15-32.

39 Corte IDH. Opinión Consultiva n. ${ }^{\circ} 4$ de 1984, donde señaló que no constituye discriminación estipular condiciones preferentes para obtener la nacionalidad costarricense por naturalización en favor de los centroamericanos, iberoamericanos y españoles, frente a los demás extranjeros.

40 Corte IDH. Opinión Consultiva 18 de 2003, donde señaló que la obligación general de respetar y garantizar los derechos humanos vincula a los Estados, independientemente de cualquier circunstancia o consideración, inclusive el estatus migratorio de las persona, debe ser protegida en todo momento.

41 Corte IDH. Opinión Consultiva 024 de 2017, sobre identidad de género, e igualdad y no discriminación a parejas del mismo sexo. Obligaciones estatales en relación con el cambio de nombre, la identidad de género, y los derechos derivados de un vínculo entre parejas del mismo sexo. 
men inválidas, arbitrarias o de subordinación que evidencien una situación de desigualdad estructural. Siempre será discutible definir quién es el mejor posicionado para determinar cuáles son los grupos sometidos o discriminados, si el Parlamento o las cortes, este punto en el caso del matrimonio igualitario en Ecuador fue zanjado por la Corte.

La Corte Constitucional de Ecuador, al enfrentarse al caso del matrimonio entre parejas del mismo sexo, analiza que el legislativo tenía la obligación de instituir -el poder jurídico para que puedan casarse las parejas del mismo sexo- y que al no conferir la ley ha quebrantado este mandato. En cuanto al test de igualdad o escrutinio estricto de igualdad, señala que la categoría "sexo" es sospechosa, siendo arbitrario un trato que se funde en ese criterio; sin embargo, esto no significa que todo trato basado en esta categoría se encuentre prohibido, sino solo en aquellos casos en donde exista discriminación y subordinación ${ }^{42}$.

De forma expresa señala la Corte que el derecho a la igualdad formal y material apoyan al matrimonio de parejas del mismo sexo $^{43}$, constituye el derecho a igual tratamiento ante la ley y el derecho a ser tratado como igual, conforme el artículo 11.2 de la Constitución de la República del Ecuador, entre otras formas de protección garantiza los derechos a la familia y al libre desarrollo de la personalidad, en consecuencia, prima facie establecen el derecho fundamental al matrimonio.

En efecto, la Corte señala que la norma constitucional identifica como una categoría sospechosa la orientación sexual, como uno de los supuestos por los que el artículo 11.2 de la Constitución prohíbe todo trato discriminatorio. En este sentido, esta categoría que ha sido desplazada del matrimonio pasa a un test de igualdad consistente en un escrutinio estricto de constitucionalidad de la ley que regula el matrimonio, considerando que no existe un fin constitucionalmente admitido, ni explícito ni implícito, que pueda invocarse para privar a parejas del mismo sexo de la posibilidad de casarse.

Para reafirmar esta conclusión, sobre el derecho material de la igualdad, considera la Corte que las parejas del mismo sexo, a más de las consecuencias jurídicas, padecen efectos simbólicos que impactan en su realidad: el hecho de no poder casarse entre sí causa efectos degradantes y/o estigmatizantes que deterioran sus vidas ${ }^{44}$. Situación que es más evidente en países con mayores desigualdades socioeconómicas como Ecuador.

En efecto, tanto en la dimensión formal como en la material, se sostiene por la Corte, la Constitución permite al legislador instituir el matrimonio entre parejas del mismo sexo, no debiendo el mismo inhibirse de proteger este derecho por guardar deferencia al constituyente, el cual, al redactar el

42 SABA. Más allá de la igualdad formal ante la ley, cit., 84.

43 Véase. Ecuador. Corte Constitucional. Sentencia 010-18-CN, considerandos 64, 65 y 66.

44 Véase ibid., considerando 66. 
artículo 67 del texto constitucional, no contempló la facultad de contraer matrimonio para las parejas del mismos sexo pero tampoco la negó, dejando esta tarea en manos del legislador. En suma, bajo este argumento se sostiene que el principio democrático tiene una intensidad baja frente a la gravedad de los derechos constitucionales como la igualdad, el libre desarrollo de la personalidad y el matrimonio, contenidos en el caso, al igual que por la exclusión socioeconómica que padecen los homosexuales, lo que afecta a la dignidad de forma intolerable. En consecuencia, "la institucionalización del matrimonio entre esas personas eliminaría al menos una de las causas de su marginación" ${ }^{45}$.

En este orden de ideas la Corte decidió involucrar elementos del escrutinio estricto de igualdad con las condiciones de discriminación real que afectan a las parejas del mismo sexo. De otro lado, saliendo del dilema de quién es el mejor sujeto para la protección de derechos, si la Corte o el Parlamento, señala que el legislador incumplió con la protección de este grupo al no tratar las condiciones del matrimonio civil en relación con la igualdad formal y material, así como ante la intolerable violación de derechos causadas por una discriminación, que no solo tiene efectos jurídicos sino físicos y psicológicos, basada en el criterio sospechoso del sexo. Concluyendo, por tanto, que es obligación de la Corte Constitucional desarrollar la protección para las parejas del mismo sexo.

\subsubsection{La incidencia de la Opinión Consultiva OC-24/17 en el}

bloque de constitucionalidad de la Constitución de Ecuador

La tensión entre rigidez constitucional y sistema abierto de protección internacional de derechos humanos que presenta la norma suprema de Ecuador, dependiendo de cómo se aborde el problema jurídico del matrimonio entre personas del mismo sexo, podría dar más de una respuesta jurídica al caso concreto: si el matrimonio igualitario supondría reformar la Constitución, o es un derecho de aplicación directa desarrollado en el sistema internacional de derechos humanos que debe integrase a la Constitución mediante el bloque de constitucionalidad. Lo dicho da cuenta del dilema que representa, nuevamente, un desacuerdo entre el voto de mayoría y el de minoría en el Caso 010-18-CN de la Corte Constitucional de Ecuador.

De un lado, si se trata de una reforma al artículo 67 de la Constitución correspondería al poder constituyente derivado seguir los respectivos procesos de enmienda o reforma parcial, según sea el caso $^{46}$. Mientras que el voto de mayoría de la sentencia, en el Caso 010-19-CN, considera que la falta de regulación del matrimonio entre parejas del mismo sexo no supone un 
límite constitucional que, de forma explícita o implícita, prohíba al legislador regular este derecho, dando por descontada la posibilidad de acudir a un proceso de reforma constitucional. En esa línea de argumentos, al verificar que el legislador tenía la obligación de proteger este derecho para evitar la discriminación jurídica y social que afecta a parejas del mismo sexo entraría en mora aquel y, en consecuencia, correspondería a la Corte Constitucional la protección de tales derechos.

La Corte considera oportuno revisar el valor jurídico de los tratados e instrumentos internacionales de derechos humanos, en la especie la CADH y la Opinión Consultiva 24/17, que desarrollan este derecho de manera más favorable para este grupo, estableciendo la necesidad de integrar el matrimonio igualitario al bloque de constitucionalidad.

Sobre este punto, las dos decisiones analizadas difieren respecto de que se incluya en la Constitución, como parte del bloque de constitucionalidad, la opinión consultiva que interpreta de manera autorizada la CADH. En la sentencia en el Caso 011-19-CN, con ponencia del juez Ramiro Ávila, se le otorga valor jurídico propio a la Opinión Consultiva OC-24/17:

¿Si la Opinión Consultiva OC-24/17 es aplicable en el sistema jurídico ecuatoriano, cuáles son los efectos jurídicos en relación con los operadores de justicia y los funcionarios públicos?

[...] Al ser la Opinión Consultiva OC-24/17 un instrumento internacional de derechos humanos directa e inmediatamente aplicable en el Ecuador, se derivan obligaciones a las distintas autoridades del Estado. En particular: (1) el deber de adecuar el sistema jurídico a los derechos reconocidos en instrumentos internacionales; (2) el control de convencionalidad de las autoridades estatales, en particular de quienes ejercen jurisdicción; (3) las relaciones entre el control de constitucionalidad y convencionalidad; (4) la responsabilidad internacional si se inobserva la Opinión Consultiva OC-24/17; y, en relación con la cultura jurídica, (4) el reto de adecuar las prácticas.

En efecto, establece que la Opinión Consultiva OC-24/17, por ser el instrumento internacional de derechos humanos que reconoce el derecho al matrimonio igualitario, debe ser aplicado de forma directa por el sistema constitucional ecuatoriano, señalando que este instrumento forma parte del bloque de constitucionalidad.

De otro lado, el juez Alí Lozada, en el Caso 010-19-CN, sostiene que no sería en sí misma la opinión consultiva el instrumento de aplicación directa, sino el artículo 17.2 de la CADH comprendida de forma hermenéutica por la interpretación que le otorga a la regulación del matrimonio en la Opinión Consultiva OC-24/17: 
Pero, en todo caso, [...] es claro que el artículo 17.2 de la Convención consagra el derecho de las parejas del mismo sexo al matrimonio, derecho que forma parte de nuestro bloque de constitucionalidad, en virtud del [...] inciso segundo del artículo 424 de la Constitución.

Así, la sentencia incluye el derecho al matrimonio entre parejas del mismo sexo en la Constitución, como una forma de vertebrar el contenido axiológico de los derechos establecidos mediante un tejido de principios, fines y valores de justicia, a la luz del artículo 424 de la Constitución que señala: "La Constitución y los tratados internacionales de derechos humanos ratificados por el Estado que reconozcan derechos más favorables a los contenidos en la Constitución, prevalecerán sobre cualquier otra norma o acto del poder público". Norma que tornaría al artículo 17.2 de la Convención y su interpretación autorizada en la Opinión Consultiva OC-24/17 parte de la Constitución, reconociendo sustantivamente el derecho de las parejas del mismo sexo al matrimonio. Estos elementos, junto al prolijo desarrollo de otros derechos y al incumplimiento del deber legislativo de proteger este derecho, permitieron a la Corte Constitucional sustraer y modular los efectos del artículo 81 del Código Civil, estableciendo: "Matrimonio es un contrato solemne por el cual dos personas se unen con el fin de vivir y auxiliarse mutuamente"47.

\section{BALANCE CRÍTICO DE LAS SENTENCIAS: MUTACIÓN O REFORMA, INTERPRETACIÓN LITERALISTA O SISTEMÁTICA}

Respecto a la Sentencia 011-19-CN se destaca la importancia que otorga al derecho internacional de los derechos humanos. En este sentido es plausible el esfuerzo que realiza la Corte, en su voto de mayoría, por hacer manifiesto el valor de la normativa internacional cuando esta reconoce derechos más favorables a las personas que las disposiciones del orden jurídico interno. En esa medida, la lectura que realiza la sentencia es en clave de complementariedad, más que de tensión, entre la disposición constitucional que regula el matrimonio y la opinión consultiva a partir de lo dispuesto por la Corte IDH. Sobre todo, porque tanto en la Sentencia 011-19-CN como en la Sentencia 010-19-CN se señala que el artículo 67 de la Constitución es una norma que utiliza un lenguaje definitorio y, por tanto, no acude a un lenguaje prescriptivo, el cual se caracteriza por mandar, prohibir o permitir determinada conducta. Ahora bien, la lectura en clave de complementariedad no resta, necesariamente, fuerza a la crítica formulada por el voto salvado, el cual, entre otras cosas, aludía a que la única forma de permitir que opere el matrimonio entre personas del mismo sexo sería la reforma constitucional. 
En consecuencia, cambiar el sentido de lo prescrito de forma taxativa por el artículo 67 del texto constitucional, esto es, que el matrimonio es entre un hombre y una mujer, no era posible por medio del método de interpretación sistemática ${ }^{48}$. En ese sentido, la tensión entre el voto de mayoría y el voto salvado podría ser analizada, también, desde los límites a la interpretación mutativa de la Constitución. Interpretación que, a decir de Hesse, supone que el límite a las posibilidades interpretativas viene dado por la imposibilidad del quebrantamiento constitucional, esto es, la desviación de una disposición constitucional clara en un caso concreto, dando paso así a la reforma constitucional a través de la interpretación de la Constitución ${ }^{49}$. De ahí que una alternativa que podría haber contemplado el voto de mayoría, para salvar la objeción formulada por el voto de minoría, fuese la emisión de una sentencia que conminara a la Asamblea Nacional de Ecuador a reformar la Constitución, en su modalidad, menos rígida, la enmienda contemplada en el artículo $441^{[50]}$, por ser un asunto que da cuenta de un avance de derechos; para que así la normativa nacional, empezando por la Constitución, guarde armonía con lo señalado con el derecho internacional de los derechos humanos. Dicho sea de paso, se hubiera aprovechado la oportunidad para que la Corte exhortara a la Asamblea Nacional ecuatoriana a enmendar también el artículo 68 de la Constitución, el cual establece que la adopción corresponderá exclusivamente a parejas de distinto sexo, con lo cual se equipararían de pleno derecho los matrimonios entre personas del mismo sexo y los matrimonios de personas heterosexuales. Ahora bien, se debe decir que la alternativa expuesta no carece de problemas, en la medida en que hubiese supuesto llevar la discusión a la sede parlamentaria, en donde no se podía asegurar que lo dispuesto por la Corte fuese cumplido, toda vez que, por ejemplo, para proceder a enmendar la Constitución se precisa de dos terceras partes de los votos de los asambleístas. En definitiva, la decisión de la Corte en la sentencia analizada se presenta como una decisión polémica, no por su intrínseco valor sustantivo, que, en últimas, defiende el derecho a la igualdad y el libre desarrollo de todas las personas, sino por el procedimiento con que se produjo, esto es, que la Corte vía interpretación dio luz verde al matrimonio de las parejas del mismo sexo, a pesar del modo como está redactado el artículo 67 del texto constitucional ecuatoriano. Artículo cuya interpretación no es pacífica en cuanto a si incluye una prohibición o deja abierta una laguna que debe ser

48 Véase ibid., voto salvado, considerandos 54 y 55.

49 Hesse. K. Escritos de derecho constitucional. P. Cruz Villalón (trad.). Madrid: Centro de Estudios Constitucionales, 1992, 49.

50 Sobre los mecanismos de reforma constitucional en Ecuador véase BENAVIDES ORDóÑEZ, J. Los procedimientos de reforma en algunas constituciones de América Latina. Un estudio normativo con particular énfasis en la Constitución ecuatoriana de 2008. En Estudios Constitucionales. N. ${ }^{\circ} 1,2018,43-44$. 
completada por los poderes públicos, en este caso por la Corte, órgano que a partir del diseño constitucional pergeñado en la Constitución de 2008 es el principal encargado para establecer los alcances, contenidos y límites de los derechos. Es pertinente, por otro lado, señalar también que aunque en el Caso 011-19-CN, el efecto fue inter partes, sentó un importante precedente al respecto; los efectos generales fueron dados en la resolución que a continuación se comentará.

La sentencia del Caso 010-19-CN, por otra parte, interpreta la Constitución de manera dinámica e integral y aplicó la ponderación de derechos, entre el principio democrático y el derecho a la igualdad, resolvió que el matrimonio entre parejas del mismo sexo es un derecho constitucional que debía regular el legislador.

El canon argumentativo, desde el planteamiento del problema general, los sub-problemas y los niveles de respuestas jurídicas, cumple con lo lógico, razonable y comprensible de la resolución del caso, calificado por la doctrina como un caso difícil. Del lado del voto de mayoría, se propone considerar que la falta de regulación del matrimonio del mismo sexo es discriminatoria. En contraste, la decisión del voto salvado es motivada desde la comprensión literal del artículo 67 de la Constitución, requiriendo de una reforma constitucional para la modificación de esta, en atención a su rigidez.

El desarrollo de esta sentencia presenta dos puntos críticos, que tienen que ver con el tratamiento de la democracia deliberativa y la ambigüedad que presenta al analizar el bloque de constitucionalidad. Es claro que en Ecuador tanto el modelo legislativo como el judicial son de adjudicación de las decisiones por parte de las autoridades que representan el poder democrático o que ejercen sus funciones de manera constitucional, mas no se construyen las decisiones desde la plena democracia deliberativa; sin embargo, es posible construir una institucionalidad menos polarizada y más dialógica que incluya a la ciudadanía y a las instituciones en una dinámica deliberativa. Es por ello que se considera una afirmación delicada en la sentencia el sostener que las decisiones legislativas son producto del sistema deliberativo ${ }^{51}$.

Asimismo, es importante que un sistema jurídico defina con precisión si un instrumento interpretativo forma parte del bloque de constitucionalidad, punto de debate que aún no está claro. En el derecho comparado cabe citar la Sentencia C-10 de 2000 expedida por la Corte Constitucional de Colombia, que resolvió negar la petición de inconstitucionalidad de la Ley 74 de 1966 que "reglamenta la transmisión de programas por los servicios de radiodifusión" ${ }^{52}$, y en relación con el rol de las opiniones consultivas en el derecho constitucional señaló que la Opinión Consultiva OC-5/83 es un criterio

51 HüBner Mendes. Constitutional Courts and Deliberative Democracy, cit., 14.

52 Véase Colombia. Corte Constitucional. Sentencias C-10 de 2000, C-288 de 2009, C-731 de 2005, C-189 de 2006 y C-187 de 2006. 
hermenéutico relevante para establecer el sentido de derechos reconocidos por la Convención, al sostener que la censura previa está prohibida. En esa ocasión, la Corte de Colombia les otorgó un criterio de apoyo hermenéutico interpretativo a las opiniones consultivas, situación distinta a la de otorgarles el valor jurídico de bloque de constitucionalidad como ocurre en Ecuador.

El bloque de constitucionalidad, como los otros instrumentos de interpretación del derecho constitucional, tiene por finalidad integrar vía jurisprudencia a la Constitución normas que no forman parte de ella; se trata de una herramienta que orienta al juez a identificar normas que no afecten la fisonomía indiscutible de la Constitución o su tejido axiológico. En ningún caso significa que todas las normas del sistema internacional de derechos humanos forman parte de la Constitución, ya que al sostener esto se volvería imposible el funcionamiento tanto de estos instrumentos como de la propia norma suprema, en la medida en que se conocería dónde inicia pero no dónde termina la Constitución. Es por ello que cada sistema debe modular los criterios jurisprudenciales para la adecuada aplicación de los mismos; así tenemos que (a) se debe precisar el número de derechos reconocidos en la Constitución; (b) se trata de un instrumento interpretativo que elimina las trabas procesales para el reconocimiento de derechos, y (c) una vez que el derecho forma parte de la Constitución es norma de control jurídico y político de los poderes democráticos ${ }^{53}$.

En suma, la jurisprudencia ecuatoriana no ha establecido con claridad la dimensión y límites de esta institución jurídica, lo que podría considerarse un riesgo en la medida en que establecer una institución sin seguros institucionales puede dar pie a que los jueces extiendan el bloque de constitucionalidad sin límites, lo que podría afectar el contenido de la Constitución y al propio control de constitucionalidad de la ley.

\section{CONCLUSIONES}

Los casos analizados coinciden en reconocer la constitucionalidad del matrimonio a las personas del mismo sexo. En los dos casos se evidenció cómo se dividió la opinión de la Corte Constitucional, planteando que existen más de dos maneras de interpretar y aplicar la Constitución y los instrumentos internacionales de derechos humanos. También, las sentencias respectivas abren la posibilidad de iniciar todo un debate para definir cuál es o si existe la respuesta correcta en los casos difíciles. No hay duda de que la finalidad de las decisiones de los votos de mayoría consiste en construir una decisión integral para la protección de derechos. Sin embargo, los caminos argumentativos para llegar a ese lugar axiológico y hermenéutico de la interpretación

53 Escudero, J. El cambio de cultura jurídica en la interpretación constitucional. En INREDH, Nuevas instituciones del derecho constitucional. Quito: INREDH, 2009, 71. 
son diferentes, es decir, los propios jueces de la mayoría de la Corte Constitucional tienen justificaciones distintas para garantizar el matrimonio en pie de igualdad. De otro lado, cabe resaltar la importancia del análisis del voto de la minoría que, en función de la rigidez y la literalidad de la Constitución, da una respuesta jurídica diametralmente diferente al caso del matrimonio.

La propuesta de una reforma constitucional para plantear la posibilidad jurídica de contraer matrimonio entre parejas del mismo sexo que propone el voto de minoría exhibe interesantes razones que descansan, en último término, en una voluntad no tan clara de los deseos del constituyente respecto a la definición de matrimonio, lo que explica los desencuentros interpretativos radicales con el voto de mayoría. Escenario que para efectos de los casos analizados supone enfrentar tradiciones jurídicas distintas respecto a los límites de la interpretación constitucional, pero que son ineludibles en la formación del derecho nacional y nos permite mostrar lo complejo de resolver casos difíciles.

En contraste, la opción de entender los casos a la luz de la interpretación integral, la adecuación a la dinámica de la sociedad o desde el principio teleológico atendiendo a la Constitución, da como resultado una interpretación progresiva, hacia la que se encamina parte de la cultura jurídica nacional de manera desafiante, ante la cual es un logro la autorización para conceder el poder de casarse a las personas del mismos sexo.

Así, las sentencias en estudio son un reflejo de lo que en los círculos académicos especializados en materia constitucional se debate, dando cuenta de los desacuerdos sobre el procedimiento a seguir para lograr la ampliación del matrimonio en Ecuador. Sin embargo, más allá de las tensiones, que son importantes, el gran reto es que tanto la ciudadanía como el Parlamento y la Corte Constitucional puedan recoger el nomos o la identidad de un pueblo heterogéneo reconocido en la Constitución, y que a partir de esa diversidad creen un vínculo de lealtad para con esta y sus valores, entre los cuales el de la igualdad de todas las personas es el que permite vertebrar el Estado constitucional de derechos y justicia ecuatoriano.

\section{REFERENCIAS}

AÑón. M. Los principios y valores que guían los derechos: igualdad. En De Lucas, J. y Rodríguez, J. (coords.), Derechos humanos y Constitución. Valencia: Tirant lo Blanch, 2018 .

ARAngo, R. ¿Hay respuestas correctas en el derecho? Bogotá: Siglo del Hombre, 2016.

BenAVIDES ORdóñez, J. Los procedimientos de reforma en algunas constituciones de América Latina. Un estudio normativo con particular énfasis en la Constitución ecuatoriana de 2008. En Estudios Constitucionales. N. ${ }^{\circ}$ 1, 2018. 
DulitzQKy, A. Principio de igualdad y no discriminación. Claroscuros de la jurisprudencia interamericana. En Anuario de Derechos Humanos. 2007.

ESCUDERO, J. El cambio de cultura jurídica en la interpretación constitucional. En INREDH, Nuevas instituciones del derecho constitucional. Quito: INREDH, 2009.

Garrorena, A. Teoría de la Constitución. Madrid: Centro de Estudios Políticos y Constitucionales, 2014.

Herrera, A. Estudio introductorio. En Ely, J. y Slagstad, R. Constitucionalismo y democracia. México, D.F.: Fondo de Cultura Económica, 2001.

Hesse, K. Escritos de derecho constitucional. P. Cruz Villalón (trad.) Madrid: Centro de Estudios Constitucionales, 1992.

Hübner Mendes, C. Constitutional Courts and Deliberative Democracy. Oxford: Oxford University Press, 2015.

Lozada, A. y Ricaurte, C. Manual de argumentación jurídica. Quito: Cedec y Corte Constitucional, 2013.

Picontó, T. Familia, matrimonio y derecho a la libre opción de la sexualidad. En De LuCAS, J. y Rodríguez, J. (coords.), Derechos humanos y Constitución. Valencia: Tirant lo Blanch, 2018.

Post, R. y Reva, S. Constitucionalismo democrático. Por una reconciliación entre Constitución y pueblo. Buenos Aires: Siglo xxI Editores, 2013.

SABA, R. Más allá de la igualdad formal ante la ley. ¿Qué les debe el Estado a los grupos desventajadas? Buenos Aires: Siglo xxI Editores, 2016.

SABA, R. Introducción. Matrimonio, autonomía e igualdad. En Alterio, M. y Niembro, R. (coords.), La Suprema Corte y el matrimonio igualitario en México, México, D.F.: UNAM, 2017.

Tushnet, M. Constitucionalismo y judicial review. Lima: Palestra, 2013.

\section{Normativa}

Ecuador. Código Civil. Registro Oficial, Suplemento 46, 24 de junio 2005.

Ecuador. Constitución de 2008. Registro Oficial 449, 20 de octubre de 2008.

Ecuador. Ley Orgánica de Garantías Jurisdiccionales y Control Constitucional. Registro Oficial, Suplemento 52, 22 de octubre de 2009.

Ecuador. Ley Orgánica de Gestión de la Identidad y Datos Civiles. Registro Oficial, Suplemento 684, 4 de febrero de 2016.

\section{Jurisprudencia}

Colombia. Corte Constitucional. Sentencia C-10 de 2000.

Colombia. Corte Constitucional. Sentencia C-731 de 2005. 
Colombia. Corte Constitucional. Sentencia C-187 de 2006.

Colombia. Corte Constitucional. Sentencia C-189 de 2006.

Colombia. Corte Constitucional. Sentencia C-288 de 2009.

Corte IDH. Opinión Consultiva OC-4/84.

Corte IDH. Opinión Consultiva OC-18/03.

Corte IDH. Opinión Consultiva OC-24/17.

Ecuador. Corte Constitucional. Sentencia 001-13-SCN-CC.

Ecuador. Corte Constitucional. Sentencia 005-13-SCN-CC.

Ecuador. Corte Constitucional. Sentencia 034-13-sCN-CC.

Ecuador. Corte Constitucional. Sentencia 10-18-CN.

Ecuador. Corte Constitucional. Sentencia 11-18-CN.

Ecuador. Corte Constitucional. Voto salvado, Caso 10-18.

Ecuador. Corte Constitucional. Voto salvado, Caso 11-18. 